\title{
Patient perspectives on continuity of care: adaption and preliminary psychometric assessment of a Norwegian version of the Nijmegen Continuity Questionnaire (NCQ-N)
}

Øystein Hetlevik ${ }^{1 *}$ D, Merethe Hustoft ${ }^{1,2}$, Annemarie Uijen ${ }^{3}$, Jörg Aßmus ${ }^{4}$ and Sturla Gjesdal ${ }^{1}$

\begin{abstract}
Background: Continuity of care is regarded as a core quality element in healthcare. Continuity can be related to one or more specific caregivers but also applies to collaboration within a team or across boundaries of healthcare. Measuring continuity is important to identify problems and evaluate quality improvement of interventions. This study aimed to assess the feasibility and psychometric properties of a Norwegian version of the Nijmegen Continuity Questionnaire (NCQ).

Methods: The NCQ was developed in The Netherlands. It measures patients' experienced continuity of care across multiple care settings and as a multidimensional concept regardless of morbidity. The NCQ comprises 28 items categorised into three subscales; two personal continuity scales, "care giver knows me" and "shows commitment", asked regarding the patient's general practitioner (GP) and the most important specialist; and one "team/cross boundary continuity" scale, asked regarding primary care, specialised care and cooperation between GP and specialist, with a total of seven factors. The NCQ was translated and adapted to Norwegian (NCQ-N) and distributed among patients referred to somatic rehabilitation ( $N=984$, response rate $34.5 \%$ ). Confirmatory factor analyses (CFA), Cronbach's alpha, intra-class correlation (ICC) and Bland-Altman plots were used to assess psychometric properties.

Results: All patients $(N=375)$ who had responded to all parts of the NCQ-N were included in CFA. The CFA fit indices (CFI 0.941, RMSEA 0.064 (95\% Cl 0.059-0.070), SRMR 0.041) support a seven-factor structure in the NCQ-N based on the three subscales of the original NCQ. Cronbach's alpha showed internal consistency (0.84-0.97), and was highest for the team/Cross-boundary subscales. The NCQ-N showed overall high reliability with ICC 0.84-91 for personal continuity factors and 0.67-0.91 for team factors, with the lowest score for team continuity within primary care.

Conclusions: Psychometric assessment of the NCQ-N supports that this instrument, based on the three subscales of the original Dutch NCQ, captures the concept of "continuity of care" among adult patients with a variety of longstanding medical conditions who use healthcare on a regular basis. However, its usefulness among varied patient groups, including younger people, patients with acute disorders and individuals with mental health problems, should be further evaluated.
\end{abstract}

Keywords: Continuity of care, Patient reported outcome measure, Healthcare, General practice, Health service research

\footnotetext{
* Correspondence: oystein.hetlevik@uib.no

${ }^{1}$ Department of Global Health and Primary Health Care, University of Bergen,

PO-box 7804, N-5020 Bergen, Norway

Full list of author information is available at the end of the article
} 


\section{Background}

Continuity of care is considered to be fundamental to quality healthcare $[1,2]$. It is associated with improved patient satisfaction, especially among patients with chronic conditions [1-3], reduced costs and decreased hospital admissions [4-6]. Thus, improving continuity is key to health professionals and other stakeholders providing higher healthcare quality [7]. Continuity of care is a multi-faceted concept [8] that has broadened in recent decades from a focus on personal continuity related to one caregiver, towards personal, informational and management continuity involving several healthcare professionals [9-11].

In general practice, personal doctoring has been highly valued and considered as a core quality element [12]. However, personal continuity and commitment is regarded to be the foundation for building trust and promoting partnerships at all levels of healthcare [13]. Furthermore, patients with serious diseases have been reported to appreciate personal attachment to their caregivers [14]. However, an elevated risk for fragmented care is likely in complex health services with large units and several professional groups [15]. Both cooperation between caregivers in teams (team continuity) and information handover during a care process (cross-boundary continuity) are considered crucial to ensuring high quality of care $[5,10]$.

The last decade has seen two major healthcare reforms in Norway, both of which aimed to improve continuity of care. When the general practitioner (GP) system in Norway was reorganised into a list patient system in 2001, one main goal was to achieve personal continuity of care by giving each inhabitant a defined regular GP who was expected to have a coordinating role [16]. In 2010, the Norwegian parliament introduced "cooperation reform", which shifted responsibility for many patients with serious conditions from hospitals to primary care that was organised by the municipalities. One aim of this reform was to improve cooperation between specialised care and local authorities, stating that "patients' needs for coordinated services are not sufficiently met" [17]. Similar reforms have been introduced in many countries [18, 19].

Measuring continuity of care is important to identify problems and evaluate interventions aimed at improving continuity of care. Continuity of care has often been assessed according to different measures of contact between the patient and different caregivers during a defined period [20, 21]. However, there are arguments for evaluating continuity of care by examining patients' experiences of provided care as the preferred perspective [21-23]. Several disease-specific, patient-reported tools have been developed to assess patients' experiences of continuity of care, but few can be generalised across different patient groups $[21,24]$.
The Nijmegen Continuity Questionnaire (NCQ) measures patients' experienced continuity of care as a multidimensional concept (personal, team and cross-boundary continuity) regardless of morbidity and across multiple care settings [25]. Furthermore, the NCQ has been confirmed to be a comprehensive, reliable and valid instrument [26].

To use an instrument such as the NCQ in a new language, there is need for linguistic translation and adaption to both the new language and context, a process referred to as cross-cultural adaption. Guidelines are given with recommendations for steps in this process [27].

This study aims to describe the adaptation of the NCQ into a Norwegian version (NCQ-N) and to assess its feasibility and psychometric properties for Norwegian patients with various chronic somatic disorders.

\section{Methods}

Norwegian and Dutch healthcare services are largely similar in that patients are assigned to a regular GP who typically works in a group practice and who has a gate-keeping role regarding use of specialised care. This similarity supports how construct validity assessments performed on the original version of the NCQ are also applicable in Norway, after adaptation to a Norwegian context.

\section{Nijmegen continuity questionnaire}

The instrument comprises 28 items that fall within the following three subscales:

- Personal continuity: care provider knows me (5 items each for the GP and most important specialist)

- Personal continuity: care provider shows commitment (3 items each for the GP and most important specialist)

- Team/cross-boundary continuity (4 items each for collaboration between care providers within general practice, within the hospital/outpatient department and between the GP and specialist).

Items are presented as statements and scored along a 5-point Likert scale ranging from "strongly disagree" to "strongly agree" with the additional option "I do not know". In the questionnaire, the items are presented in five groups of items, two item groups concerning personal continuity related to the GP and the most important specialist and three item groups with the team/cross boundary scale related to primary care, specialised care and between the GP and specialist. Both the subscales regarding personal continuity are presented as part of the same item group for the GP and specialist, respectively. The participants are instructed to skip the item groups related to the GP and specialist if they had not been in contact in the last 12 months and the other item groups if they were not seen as applicable. Principally, the model has three subscales, but the questions regarding the subscale "personal continuity - healthcare provider knows 
me" and "personal continuity- healthcare provider shows commitment" are used for both the GP and specialist, and the team/cross boundary subscale is applied to three team contexts: in primary care, in specialised care, and between the GP and specialist, giving a seven-factor model.

\section{Translation and adaption}

The NCQ was translated into Norwegian as recommended in a guideline by Beaton et al. using forward and backward translations based on the original Dutch version with the help of both linguistic and healthcare professionals from both countries [27]. Most general practices in The Netherlands include several healthcare professionals including physiotherapists, counsellors, and health visitors. However, general practices in Norway are usually only serviced by 1-5 GPs who are supported by "secretaries" or nurses. Therefore, for the adaptation to Norwegian context we found it necessary to broaden the scope of the primary care related team continuity items to include cooperation between GPs, nurses, and allied health professionals such as physiotherapists in primary care. Other items remained similar to that of the original, only adapted to the Norwegian language after discussion in the research group and in a pilot test. Based on discussion in the research group and testing the questions in a smaller sample, a direct translation of "very" as used in seven of twelve items was found unnatural in describing a relationship to a professional in the Norwegian language, and was thus left out. In back translation, these items seemed less loaded. We decided to give priority to natural language at the cost of generating a problem with comparison of grading of scales across countries.

The same ratings along a 5-point Likert scale, with an additional option of "I do not know," were used.

The final version of the NCQ-N was tested on 33 patients in rehabilitation institutions who filled in the whole questionnaire package with research personnel available and were instructed to ask for clarifications. This process revealed no problems in understanding the NCQ-N content.

\section{Study population and data collection}

A cross-sectional survey of patients referred to seven specialised rehabilitation institutions in Western Norway was conducted in the first six months of 2015. Among the 2852 invited to participate, 991 returned the questionnaire, but 7 patients were excluded because they had not given written consent for further use of data. In total, 984 patients were included giving a response rate of $34.5 \%$. Nearly half of patients got a postal invitation at referral and returned the questionnaires by post before the rehabilitation stay and the others were invited when arriving the rehabilitation institution and filled out the questionnaire when starting the stay. Response rates were similar with both ways of recruitment.

The NCQ-N was distributed to the patients as part of a package of validated survey instruments to measure health, quality of care, function and participation in society. We also included questions about health problems and use of healthcare during the previous 12 months. The health problems of the patients were described by combining reason for referral given by GP or specialist, the diagnoses used by rehabilitation institutions and diseases over the last 12 months as reported by the patients and grouped into musculoskeletal, cardiovascular, respiratory, neurological, cancer, endocrinology, urinary tract and mental health problems (Table 1). Comorbidities are described by summing up the number of these groups of diseases for each patient.

Data from all included participants were assessed to examine response patterns of the different NCQ-N items and subscales and to analyse for internal consistency using Cronbach's alpha.

Because the participants were instructed to skip an item group if the items were not seen as applicable, e.g., questions about the specialists for patients who have not seen a specialist, the data contained entire item groups left empty. Assuming that completely empty item groups indicate that the questions were not applicable, we used two grades of restrictions. First, we selected all patients with responses, including "I do not know", in all item groups $(N=375)$. Then, for sensitivity analyses we also selected a sample with responses to the item groups about GPs and specialists, but not necessarily the team/ cross-boundary items $(N=652)$.

Test of reproducibility (test-retest) was based on a randomly selected sample of participants $(N=116)$ who answered all survey questions again two weeks after their first response.

\section{Statistical analyses}

A subscale was calculated as the mean of all items in the subscale, excluding cases with more than one item missing. In analyses we treated "I do not know" as a missing.

Psychometric properties of the NCQ-N were assessed using confirmatory factor analyses (CFA) with robust maximum likelihood estimation (Yuan-Bentler-correction) and Cronbach's alpha.

In CFA missing was handled by Full Information Maximum Likelihood (FIML). Using this method we found it most correct to include only respondents who had responded to all item groups $(N=375)$, and not estimate values for patients who had not found the item group applicable. However, for sensitivity analyses we also used a less restrictive sample of 652 , described above.

In CFA, the following fit indices were calculated, with values indicating a good fit within parentheses: root 
Table 1 Characteristics of the study population recruited in a survey among patients referred to somatic rehabilitation in Western Norway

\begin{tabular}{|c|c|c|c|}
\hline & $\begin{array}{l}\text { Study population } \\
\% \\
(N=984)\end{array}$ & $\begin{array}{l}\text { Non-responders } \\
(\%) \\
(N=1868)\end{array}$ & $P$ value \\
\hline \multicolumn{4}{|l|}{ Patient gender } \\
\hline Female & 63.4 & 67.2 & $0.043^{*}$ \\
\hline Male & 36.6 & 32.8 & \\
\hline Age (mean(SD)) & $58.1(14.1)$ & $55.6(16.7)$ & $0.001^{* *}$ \\
\hline \multicolumn{4}{|c|}{ Proportions in age groups } \\
\hline$<40$ years & 10.2 & 17.2 & $<0.001^{*}$ \\
\hline 40-49 years & 17.6 & 21.0 & \\
\hline 50-59 years & 24.7 & 22.5 & \\
\hline 60-69 years & 25.4 & 15.8 & \\
\hline$\geq 70$ years & 22.1 & 23.5 & \\
\hline \multicolumn{4}{|c|}{ Reported diseases, grouped } \\
\hline Musculoskeletal & 70.9 & & \\
\hline Cardiovascular & 35.5 & & \\
\hline Respiratory & 23.3 & & \\
\hline Neurology & 13.8 & & \\
\hline Cancer & 15.4 & & \\
\hline Endocrinology & 16.5 & & \\
\hline Skin & 21.4 & & \\
\hline Urinary tract & 4.6 & & \\
\hline Mental health & 23.9 & & \\
\hline
\end{tabular}

Sum reported diseases, according to list above

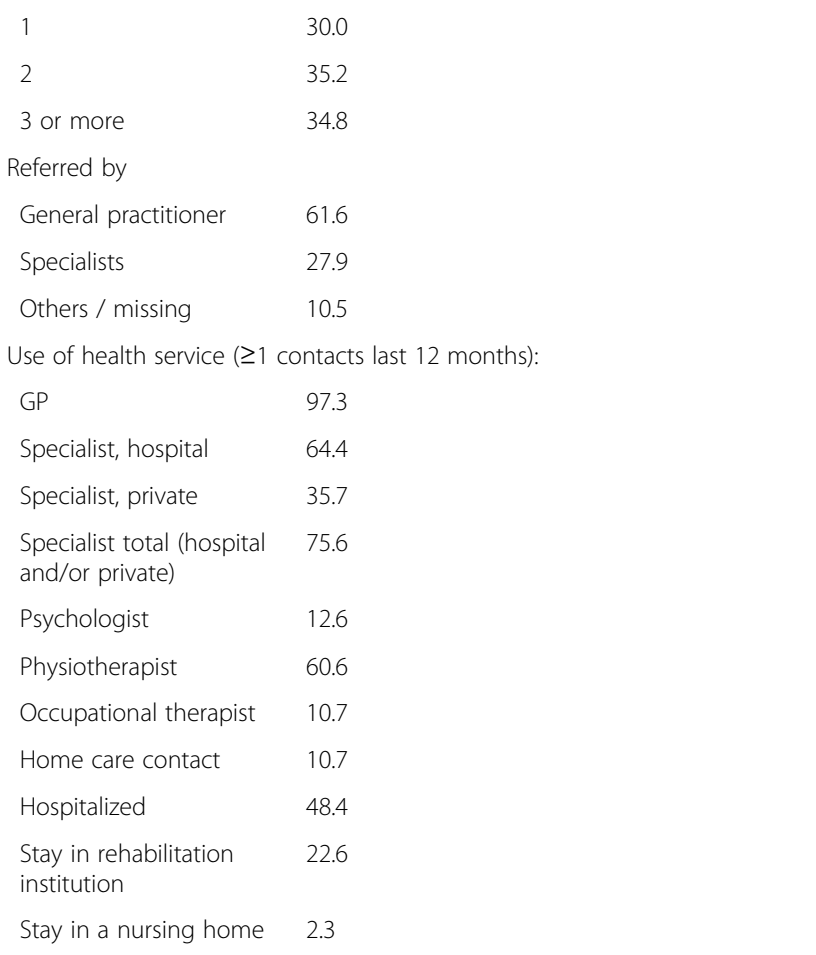

*Pearson chi square. ${ }^{* *}$ Student T-test mean square error of approximation (RMSEA) $(<0.05$ indicates a good fit and up to 0.08 mediocre fit) [28], comparative fit index (CFI) (> 0.9) [29], standardized root mean square residual (SRMR) $(<0.08)$ [30], the relative/ normed chi-square $\left(\mathrm{X}^{2} / \mathrm{df}<2\right.$ good, $<5$ acceptable) and chi-square test $(p>0.05)[29,31,32]$.

Cronbach's alpha was considered satisfactory between 0.70 and 0.95 [33]. We also present the item-rest correlations, to test the correlation between each item in a subscale and the subscale without the actual item.

If more than $15 \%$ of the samples have the highest or lowest possible score, referred to as floor or ceiling effect, the instrument's ability to discriminate between responses is reduced [33]. We therefore estimated the proportion with highest and lowest possible scores in all subscales.

Correlation between subscales was analysed using Pearson product-moment correlation. A correlation coefficient between 0.3 and 0.5 was considered moderate, and $>0.5$ a strong correlation [34].

Intra-class correlation (ICC) was used in the test-retest analysis using a two-way mixed effect model with absolute agreement, and ICC $>0.70$ indicates acceptable reproducibility [33].

The statistical program R 3.3 [35] with the package lavaan 0.5 [36] was used to perform the factor analyses; otherwise, Stata Statistical Software (Release 14; College Station, TX, USA) was used. The graphics were created using Matlab 9.0 (The MathWorks Inc., Natick, MA).

\section{Results}

The characteristics of the study population $(N=984)$ are shown in Table 1, compared with some characteristics of the non-responders in the survey.

The responses to different items in the NCQ-N are described in Table 2. In the total sample of 984, only 15 skipped the item group concerning GPs, and "I do not know" was chosen for $0.2 \%-6.4 \%$ in this item group. These measures were markedly higher in the other item groups. The item group related to team continuity within specialised care was skipped by $45 \%$ of respondents. The proportion answering "I do not know" was highest regarding team continuity within primary care, with figures slightly above $20 \%$.

There was a high proportion of maximum scores for the items regarding continuity with the GP, indicating a ceiling effect on item level, highest for the item referring to "knowing my medical history well", where $40 \%$ strongly agreed (for item contents, see Table 3). Regarding specialists, there was a floor effect, with $17 \%-20 \%$ of respondents using the lowest score in four of the eight items.

\section{Factor structure}

The fit indices found in the two different subsamples were rather similar but best in the least strict model 
Table 2 Responses to each items ${ }^{a}$ in the Norwegian version of Nijmegen Continuity Questionnaire (NCQ-N) in a survey among patients referred to somatic rehabilitation in Western Norway $(N=984)$

\begin{tabular}{|c|c|c|c|c|c|c|c|}
\hline \multirow[t]{2}{*}{ Item groups } & \multicolumn{4}{|c|}{ Responses to Likert scale $1-5^{\mathrm{b}}$} & \multirow{2}{*}{$\begin{array}{l}\text { Do not know } \\
\text { n (\%) }\end{array}$} & \multicolumn{2}{|l|}{ Missing $^{c}$} \\
\hline & $\mathrm{n}(\%)$ & Mean (SD) & $\%$ lowest & $\%$ highest & & $\begin{array}{l}\text { All within item } \\
\text { group, } \mathrm{n}(\%)\end{array}$ & other, $\mathrm{n}(\%)$ \\
\hline \multicolumn{8}{|l|}{ About GP } \\
\hline GP1 & $955(97.1)$ & $3.99(0.95)$ & 2.0 & 33.3 & $2(0.2)$ & $15(1.5)$ & $12(1.2)$ \\
\hline GP1 & $955(97.1)$ & $4.02(0.84)$ & 1.6 & 40.2 & $9(0.9)$ & $15(1.5)$ & $5(0.5)$ \\
\hline GP3 & $932(94.7)$ & $4.19(0.80)$ & 1.0 & 37.6 & $14(1.4)$ & $15(1.5)$ & $23(2.3)$ \\
\hline GP4 & $907(92.2)$ & $3.58(1.15)$ & 5.1 & 24.9 & $43(4.4)$ & $15(1.5)$ & $19(1.9)$ \\
\hline GP5 & $918(93.3)$ & $3.63(1.07)$ & 3.4 & 21.4 & $30(3.1)$ & $15(1.5)$ & $21(2.1)$ \\
\hline GP6 & $878(89.2)$ & $3.36(1.21)$ & 8.9 & 19.1 & $64(6.5)$ & $15(1.5)$ & $27(2.7)$ \\
\hline GP7 & $900(91.5)$ & $3.78(0.98)$ & 3.6 & 24.0 & $40(4.1)$ & $15(1.5)$ & $29(3.0)$ \\
\hline GP8 & $882(89.6)$ & $3.41(1.10)$ & 6.1 & 17.0 & $57(5.8)$ & $15(1.5)$ & $30(3.1)$ \\
\hline \multicolumn{8}{|c|}{ Team primary care } \\
\hline TPC1 & $454(46.1)$ & $2.92(1.00)$ & 9.5 & 4.9 & $209(21.2)$ & $316(32.1)$ & $5(0.5)$ \\
\hline TPC2 & $428(43.5)$ & $2.91(0.92)$ & 7.7 & 4.2 & $230(23.4)$ & $316(32.1)$ & $10(1.0)$ \\
\hline TPC3 & $456(46.3)$ & $2.95(0.99)$ & 8.8 & 4.6 & $200(20.3)$ & $316(32.1)$ & $12(1.2)$ \\
\hline TPC4 & $438(44.5)$ & $2.76(0.99)$ & 11.6 & 3.9 & $220(22.4)$ & $316(32.1)$ & $10(1.0)$ \\
\hline \multicolumn{8}{|c|}{ About specialist } \\
\hline SP1 & $617(62.7)$ & $2.94(1.18)$ & 13.0 & 10.2 & $32(3.3)$ & $332(33.7)$ & $3(0.3)$ \\
\hline SP2 & $586(59.6)$ & $3.48(1.08)$ & 5.1 & 16.0 & $57(5.8)$ & $332(33.7)$ & $9(0.9)$ \\
\hline SP3 & $556(56.5)$ & $3.53(1.05)$ & 4.7 & 16.9 & $79(8.0)$ & $332(33.7)$ & $17(1.7)$ \\
\hline SP4 & $563(57.2)$ & $2.57(1.17)$ & 20.3 & 7.5 & $75(7.6)$ & $332(33.7)$ & $14(1.4)$ \\
\hline SP5 & $574(58.3)$ & $2.71(1.18)$ & 17.4 & 7.7 & $62(6.3)$ & $332(33.7)$ & $16(1.6)$ \\
\hline SP6 & $535(54.4)$ & $2.95(1.14)$ & 17.4 & 7.9 & $105(10.7)$ & $332(33.7)$ & $12(1.2)$ \\
\hline SP7 & $558(56.7)$ & $3.31(1.11)$ & 9.9 & 13.3 & $83(8.4)$ & $332(33.7)$ & $11(1.1)$ \\
\hline SP8 & $534(54.3)$ & $2.86(1.10)$ & 17.4 & 8.1 & $101(10.3)$ & $332(33.7)$ & $17(1.7)$ \\
\hline \multicolumn{8}{|c|}{ Team specialised care } \\
\hline TSP1 & $447(45.4)$ & $3.31(1.03)$ & 6.9 & 8.8 & $92(9.4)$ & $443(45.0)$ & $2(0.2)$ \\
\hline TSP2 & $430(43.7)$ & $3.34(0.99)$ & 5.4 & 8.8 & $106(10.8)$ & $443(45.0)$ & $5(0.5)$ \\
\hline TSP3 & $438(44.5)$ & $3.28(1.01)$ & 6.6 & 8.5 & $96(9.8)$ & $443(45.0)$ & $7(0.7)$ \\
\hline TSP4 & $426(43.3)$ & $3.14(1.06)$ & 8.9 & 8.5 & $112(11.4)$ & $443(45.0)$ & $3(0.3)$ \\
\hline \multicolumn{8}{|c|}{ Between GP and specialist } \\
\hline TB1 & $534(54.3)$ & $3.43(0.98)$ & 5.2 & 9.9 & $136(13.8)$ & $306(31.1)$ & $8(0.8)$ \\
\hline TB2 & $502(51.0)$ & $3.27(0.96)$ & 5.2 & 8.8 & $161(16.4)$ & $306(31.1)$ & $15(1.5)$ \\
\hline TB3 & $524(53.3)$ & $3.37(0.98)$ & 5.5 & 9.4 & $139(14.1)$ & $306(31.1)$ & $15(1.5)$ \\
\hline TB4 & $504(51.2)$ & $3.21(1.00)$ & 6.6 & 8.3 & $163(16.6)$ & $306(31.1)$ & $11(1.1)$ \\
\hline
\end{tabular}

a) The content of items are shown in Table 3

b) Mean score based in Likert scale 1-5: 1 = strongly disagree, 2 = disagree, $3=$ neutral, $4=$ agree, $5=$ strongly agree with an additional option to answer, "I do not know"

c) Missing on all item within an item group is interpreted as a response to the instruction to skip the item group when seen as not applicable by the respondent

$(N=625)$. However, in this sample the proportion of missing, including "I do not know", was up to $50 \%$ in some items. Therefore, we chose to present data for the strictest sample $(N=375)$ with $19 \%-30 \%$ missing, including "I do not know", in the team factors; $8 \%-$ $16 \%$ missing items in all factors related to specialist; and less than $6 \%$ in items regarding GPs. This subsample had a higher proportion of male responders $(41.9 \%)$ than the total study sample (Table 1 ), and mean age was 57.2 years, compared with 58.1. In this subsample, three or more diseases were more often reported (42.1\% compared with 34.8\%), but musculoskeletal problems were less frequent $(66.9 \%$ compared with $70.9 \%$ ). 
Table 3 Subscales scores and measures of internal consistency within subscales in a Norwegian version of Nijmegen Continuity Questionnaire used among patients referred to somatic rehabilitation

\begin{tabular}{|c|c|c|c|}
\hline Personal continuity - care provider knows me & GP & Specialist & \\
\hline Subscale items: & $\operatorname{IRC} C^{a}$ & $\operatorname{IRC} C^{a}$ & \\
\hline I know this care provider well & 0.78 & 0.81 & \\
\hline This care provider knows my medical history well & 0.80 & 0.82 & \\
\hline $\begin{array}{l}\text { This care provider always remembers what he/she } \\
\text { did during my last visit(s) }\end{array}$ & 0.76 & 0.75 & \\
\hline This care provider knows my family circumstances well & 0.75 & 0.77 & \\
\hline $\begin{array}{l}\text { This care provider knows well what I do in my } \\
\text { day-to-day life }\end{array}$ & 0.72 & 0.80 & \\
\hline Total subscale score (SD) & $3.92(0.82)$ & $3.05(1.00)$ & \\
\hline Patients with lowest subscale score (floor effect), n (\%) & 0.7 & 3.6 & \\
\hline Patients with highest subscale score (ceiling effect), n (\%) & 14.7 & 5.2 & \\
\hline Internal consistency (Cronbach alpha) & 0.91 & 0.92 & \\
\hline Personal continuity - care provider shows commitment & GP & Specialist & \\
\hline Subscale items: & $\operatorname{IRC} C^{a}$ & $\operatorname{IRC} C^{a}$ & \\
\hline $\begin{array}{l}\text { This care provider contacts me when necessary without } \\
\text { me having to ask him/her to do so }\end{array}$ & 0.68 & 0.75 & \\
\hline $\begin{array}{l}\text { This care provider knows well what I think is important } \\
\text { when it comes to my care }\end{array}$ & 0.68 & 0.76 & \\
\hline $\begin{array}{l}\text { This care provider maintains enough contact with me } \\
\text { when I am seen by other care providers }\end{array}$ & 0.73 & 0.79 & \\
\hline Total subscale score (SD) & $3.51(0.96)$ & $3.05(1.0)$ & \\
\hline Patients with lowest subscale score (floor effect), n (\%) & 3.1 & 9.1 & \\
\hline Patients with highest subscale score (ceiling effect), n (\%) & 11.8 & 5.4 & \\
\hline Internal consistency (Cronbach alpha) & 0.84 & 0.88 & \\
\hline Team/cross-boundary continuity - & $\begin{array}{l}\text { within primary } \\
\text { care }\end{array}$ & $\begin{array}{l}\text { within specialized } \\
\text { care }\end{array}$ & $\begin{array}{l}\text { between GP and } \\
\text { specialist }\end{array}$ \\
\hline Subscale items: & $\operatorname{IRC} C^{a}$ & $\mathbb{R} C^{a}$ & $\operatorname{IRC} C^{a}$ \\
\hline $\begin{array}{l}\text { These care providers pass on information to each } \\
\text { other well }\end{array}$ & 0.97 & 0.92 & 0.86 \\
\hline These care providers work together well & 0.89 & 0.94 & 0.90 \\
\hline $\begin{array}{l}\text { The care given by these care providers is } \\
\text { well-connected }\end{array}$ & 0.89 & 0.91 & 0.85 \\
\hline $\begin{array}{l}\text { These care providers always know well what } \\
\text { the other care providers have done }\end{array}$ & 0.88 & 0.88 & 0.84 \\
\hline Total subscale score (SD) & $2.88(0.91)$ & $3.26(0.98)$ & $3.33(0.91)$ \\
\hline Patients with lowest subscale score (floor effect), n (\%) & 5.4 & 5.1 & 3.6 \\
\hline Patients with highest subscale score (ceiling effect), n (\%) & 2.8 & 6.7 & 6.8 \\
\hline Internal consistency (Cronbach alpha) & 0.96 & 0.97 & 0.95 \\
\hline
\end{tabular}

altem rest correlation (IRC): Correlation between the actual single item and the subscale without this single item

The 7-factor model according to the original NCQ fitted the data best [26] (see Fig. 1), compared with a model treating personal continuity as one factor and a two-layer model (see Additional file 1). The factor loadings showed relatively similar values for most items in all seven latent factors. The fit indices for this 7-factor model showed: CFI 0.941, RMSEA 0.064 (95\% CI 0.059-
0.070), SRMR 0.041, and chi-square $841.5(p<0.05)$ with 329 degrees of freedom giving $\mathrm{X}^{2} / \mathrm{df}=2.6$.

\section{NCQ-N single items and subscales}

The item group in relation to personal continuity was divided into two subscales, in line with the original NCQ [26], and as supported by the present CFA (Fig. 1). 


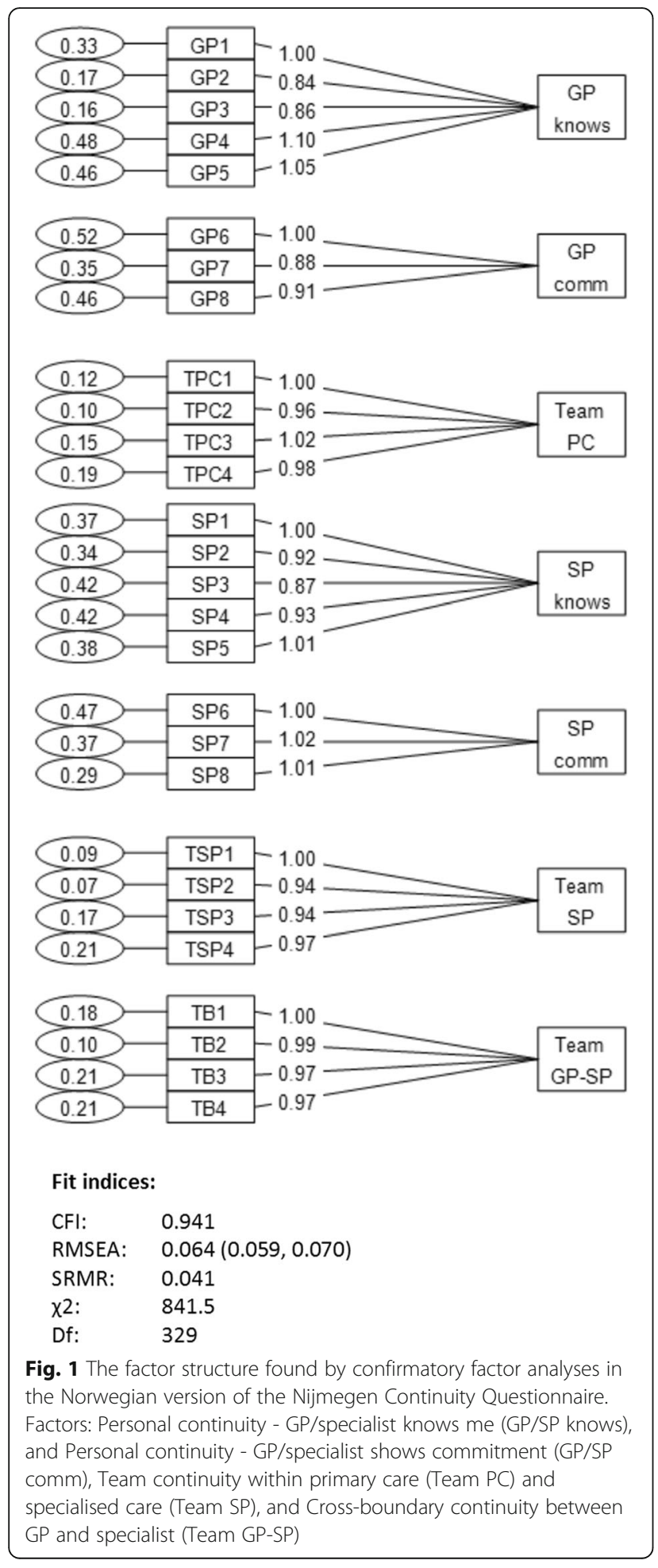

The subscales scores are shown in Table 3, where the items constituting the scales are also listed. Cronbach's alpha scores were between 0.84 and 0.97 , with highest internal consistency found for the team/cross boundary scales (Table 3).
In the two subscales measuring personal continuity for GPs, $14.7 \%$ and $11.8 \%$ had maximal scores, while the scores for the other subscales ranged from $2.2 \%$ to $6.1 \%$. The lowest possible score was seen in between $0.7 \%$ and $9.1 \%$ in the different sub scales.

A strong correlation was found between the "knows me" and "shows commitment" subscales for GPs and specialists, respectively; however, a low to moderate correlation was identified between these subscales for GPs and specialists (Table 4). Moderate to strong correlations were found between all personal continuity scores and the cross-boundary continuity with correlation coefficients between 0.41 and 0.60 .

\section{Test-retest}

Test-retest reliability was assessed using ICC in a separate sample from the main survey (Table 5). The scores concerning team continuity in primary care had the lowest reliability with an ICC of 0.67 , while other factors had an ICC in the range of 0.81-0.91. In the Bland-Altman plots, the mean difference in the scores for continuity in primary care was in line with that of other subscales, but the range of the $95 \%$ limits of agreement was larger compared with that of other subscales. The Bland-Altman plots of the subscales with highest and lowest ICC, "personal continuity- GP shows commitment" and team continuity in primary care, are presented as illustrations in Fig. 2.

\section{Discussion}

\section{Main findings}

Psychometric assessment based on test-retest, Cronbach's alpha and CFA indicated that the three subscales from the original NCQ can measure continuity of care regarding different caregivers and team contexts among patients with chronic conditions in a Norwegian setting.

\section{NCQ-N assessment}

Our findings show that a seven-factor model could be used to report patient perspectives of continuity in healthcare as a summary of the underlying single items constituting the latent factors. Fit indices were overall acceptable or good; however, a significant chi-squared test indicated possible problems with the model, which could be explained by the high correlation found between subscales.

Cronbach's alpha was above that recommended for subscales concerning team/cross-boundary continuity. Additionally, the item rest correlations were high on these subscales, indicating a possible overlap in content between single items [33].

There is a marked ceiling effect on single items constituting the personal continuity scales regarding GPs. However, the "GP knows me" scale showed a proportion 
Table 4 Correlation between the subscale scores in the Norwegian version of the Nijmegen Continuity Questionnaire

\begin{tabular}{|c|c|c|c|c|c|c|c|c|}
\hline & \multirow[b]{2}{*}{$\mathrm{N}$} & \multicolumn{4}{|c|}{ Personal continuity } & \multicolumn{3}{|c|}{ Team/cross boundary continuity } \\
\hline & & GP knows me & $\begin{array}{l}\text { GP shows } \\
\text { commitment }\end{array}$ & $\begin{array}{l}\text { Specialist } \\
\text { knows me }\end{array}$ & $\begin{array}{l}\text { Specialist shows } \\
\text { commitment }\end{array}$ & $\begin{array}{l}\text { Within primary } \\
\text { care }\end{array}$ & $\begin{array}{l}\text { Within specialised } \\
\text { care }\end{array}$ & $\begin{array}{l}\text { Between GP } \\
\text { and specialist }\end{array}$ \\
\hline \multicolumn{9}{|l|}{ Personal continuity } \\
\hline GP knows me & 923 & 1.00 & & & & & & \\
\hline GP shows commitment & 900 & $0.73^{* *}$ & 1.00 & & & & & \\
\hline Specialist knows me & 563 & $0.25 * *$ & $0.26^{* *}$ & 1.00 & & & & \\
\hline Specialists shows commitment & 552 & $0.22^{* *}$ & $0.34^{* *}$ & $0.82^{* *}$ & 1.00 & & & \\
\hline \multicolumn{9}{|l|}{ Team/cross boundary continuity } \\
\hline Within primary care & 426 & $0.31^{* *}$ & $0.41^{* *}$ & $0.32^{* *}$ & $0.41^{* *}$ & 1.00 & & \\
\hline Within specialised care & 432 & 0.07 & $0.15^{* *}$ & $0.39^{* *}$ & $0.41^{* *}$ & $0.43^{* *}$ & 1.00 & \\
\hline Between GP and specialist & 499 & $0.46^{* *}$ & $0.60^{* *}$ & $0.41^{* *}$ & $0.50^{* *}$ & $0.52^{* *}$ & $0.50^{* *}$ & 1.00 \\
\hline
\end{tabular}

of maximal scores $(14.7 \%)$ that is slightly below to the recommended maximum of $15 \%$ for a well-designed instrument [33]. The subscale "GP shows commitment" also had a high proportion with maximal scores (11.8\%). These findings may reflect the change of loading by removing "very" in the adaptation process. However, regarding the specialist, the single items in subscales showed a floor effect with equally worded items asked for GPs, so the effect of phrasing the items in the adaptation process is not quite clear. In subscales, this adaptation to the Norwegian language appeared to result in acceptable scale properties. On the other hand, a direct comparison of scale scores with the original Dutch version should not be done since the "loading" of some items is changed. However, such comparisons should always be done with precaution since response styles differs between countries and languages [37].

There was very high correlation between the personal continuity scales for GPs and specialists, respectively, but moderate to low correlation comparing GP and specialist scores. This may reflect that patients with more comprehensive care by a specialist have a less close bond with their GP. The cross-boundary continuity scale correlates moderate to high to the all other scales, and might indicate that continuity at different levels is connected in some way. Not surprisingly, there was low correlation between personal continuity related to GPs and team continuity within specialised care. However, reported personal continuity regarding specialists showed moderate to strong correlation to all team settings. This indicates that a patient with need for specialised care also experiences better continuity of care related to different caregivers. This pattern is similar in the Dutch version [26].

Questions regarding team continuity at the primary care level had the lowest ICC, compared with the other factors. The introduction to this item group in the questionnaire was changed in the NCQ-N to include health professionals working in primary healthcare with the same patients as the GPs, as a replacement for team continuity within the Dutch GP practices. However, patients may have experienced difficulty distinguishing

Table 5 Reliability of the subscales in the Norwegian version of the Nijmegen Continuity Questionnaire

\begin{tabular}{|c|c|c|c|c|c|}
\hline & \multirow[b]{2}{*}{$\mathrm{N}$} & \multicolumn{2}{|c|}{ Intra-class correlation } & \multicolumn{2}{|l|}{ Bland-Altman plot } \\
\hline & & Coefficient & $95 \% \mathrm{Cl}$ & Mean difference & $95 \%$ limits of agreement \\
\hline \multicolumn{6}{|l|}{ Personal continuity } \\
\hline - GP knows me & 112 & 0.89 & 0.84 to 0.93 & 0.126 & -0.877 to 1.130 \\
\hline - GP shows commitment & 107 & 0.91 & 0.87 to 0.94 & 0.051 & -1.016 to 1.118 \\
\hline - Specialist knows me & 58 & 0.84 & 0.72 to 0.91 & -0.238 & -1.673 to 1.197 \\
\hline - Specialist shows commitment & 54 & 0.88 & 0.79 to 0.93 & -0.148 & -1.482 to 1.185 \\
\hline \multicolumn{6}{|l|}{ Team/cross boundary continuity } \\
\hline - Within primary care & 52 & 0.67 & 0.42 to 0.81 & -0.128 & -1.942 to 1.686 \\
\hline - Within specialised care & 38 & 0.81 & 0.64 to 0.90 & -0.228 & -1.557 to 1.101 \\
\hline - Between GP and specialist & 48 & 0.91 & 0.84 to 0.95 & -0.106 & -1.209 to 0.997 \\
\hline
\end{tabular}

Based on a sample $(N=116)$ of participant in a study among patients referred to somatic rehabilitation in Western Norway 

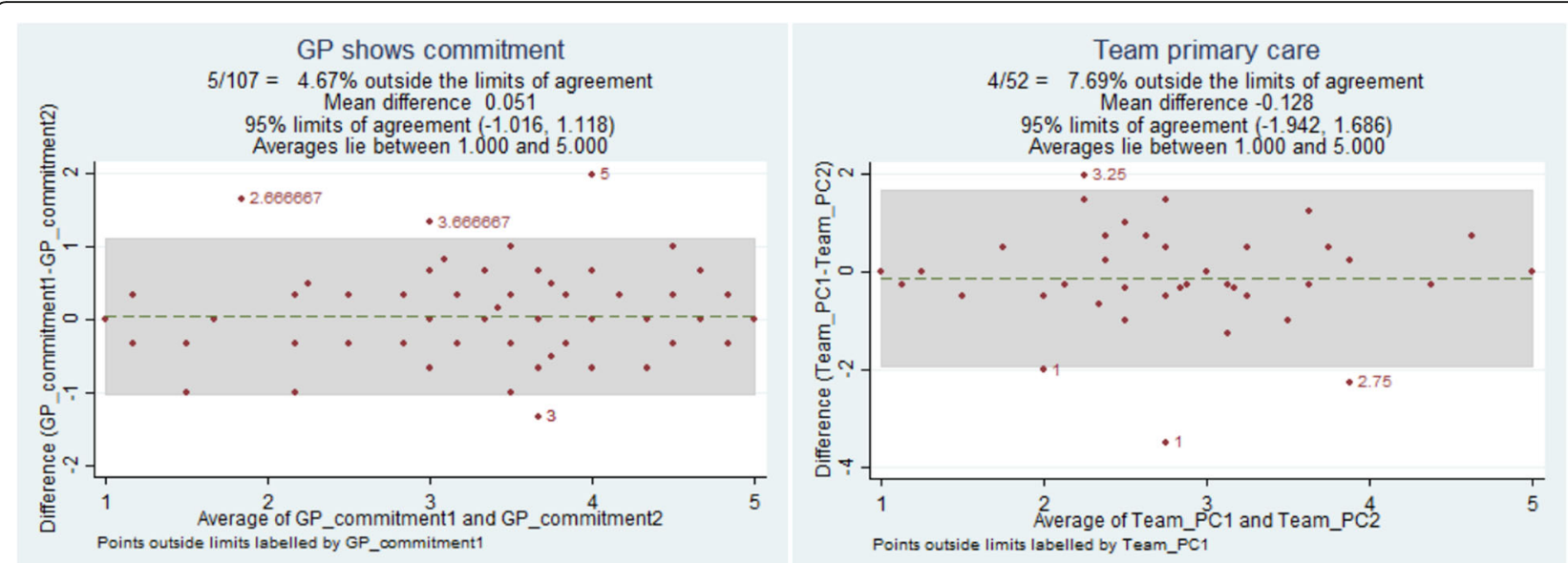

Fig. 2 Bland-Altman plots to test reliability, exemplified by the subscales for "Personal continuity -GP shows commitment" and team continuity in primary care

between the different care providers, which may explain why this subscale had the lowest reliability compared with all other subscales. Thus, this adaption of the NCQ-N requires further evaluation.

When testing the original version of the $\mathrm{NCQ}$, the questionnaires were distributed directly to the patients by their GPs or their specialists [26]. The patients had at least one chronic condition, and participants were assumed to have had contact with both GPs and hospital specialists. In the present study, questionnaires were distributed by mail or personally at the rehabilitation institution, outside the patients' usual healthcare settings. Our presumption was that most of these patients had contact with GPs, specialists and other healthcare professionals during the last 12 months because they were referred to a multidisciplinary rehabilitation program. This was apparently not the case, since the majority of missing responses in the NCQ-N were due to skipping item groups in the questionnaire, as the patients were instructed to do in the introduction to each item groups if not seen applicable. However, because some participants seemed to consider groups of items as not applicable despite reporting healthcare contacts that should have given them experience with the actual services, a more instructive introduction to each item group should be considered. The team/cross-boundary scales had $10 \%-20 \%$ with "I do not know" as a response, indicating difficulties in evaluating the informational or management continuity within healthcare.

In future research to test psychometric properties of the NCQ-N, it would have been preferable to include patients with a more uniform use of healthcare. This could be achieved by using the NCQ-N related to more specific care pathways, as COPD, rheumatological or neurological diseases with patient groups using both primary care and specialised care. Such an approach would make all parts of the questionnaire more relevant for most patients.

Despite problems with missing responses in our setting, the present psychometric analyses indicate that the NCQ-N can be a valuable instrument in research and quality development in Norwegian health services. Owing to policy changes, primary care is intended to take greater responsibility for more patient groups [17]. Still, physicians have the main responsibility for medical treatment [16], but more often they do their work in cooperation with other health care professionals at all levels of healthcare $[15,18]$. To follow the patient's experience of personal continuity of care related to GPs and specialist is therefore a useful quality control during changes $[1,13-15,18]$. At the same time, continuity across professional groups also needs assessment from a patient perspective [10, 21, 22]. The structure of NCQ giving the patients instruction to skip not applicable items groups, makes this a generic instrument that can be used across care pathways for different conditions and in different geographical areas. It can also be used to reflect changes over time and between patient groups.

\section{Study strengths and limitations}

One study strength is that the study sample for psychometric analyses consisted of patients with different somatic and mental conditions, and a broad experience with healthcare.

One weakness is low response rate in the survey and our limited information about the non-respondent group. This limits claims of representativeness. The NCQ-N was distributed as a part of a larger battery of questionnaires. This may have decreased motivation to participate in general and partly explain a low response rate in the survey. How to adapt the NCQ to a large population survey setting deserves further study. 
Further, only 375 respondents had answered related to all item groups and were included in the CFA. However, this is a sufficient number considering the total of 28 questionnaire items, and is above the recommended limit of 4-10 participants per item [33]. Additionally, the subsample with response to all parts of the NCQ-N, used for validity assessment, was largely similar to the total sample of study participants, but the subsample's reported higher disease burden less dominated by musculoskeletal problems and a greater use of healthcare were the most marked differences.

One study design limitation is that testing of construct validity was not included. This could have been addressed by comparing the NCQ-N to other instruments that measure continuity of care, validated in Norway, but no such instruments were identified. However, we tested the NCQ-N in healthcare settings similar to those used for validating the original version, and adapted according to recommendations [27]. The construct "continuity of care" is outlined extensively in international literature [10] and we believe that interpretation of this construct is similar across countries with similar social and healthcare systems to The Netherlands and Norway. The comprehensive work that was done when selecting the key dimensions of the NCQ and the testing of construct validity should also apply to the NCQ-N [25].

\section{Conclusions}

Based on a limited number of participants, we chose to present this as a preliminary psychometric assessment of the NCQ-N. However, despite the referred limitations, the NCQ-N seems to be a valid instrument that can be used in future evaluations of healthcare performance and quality assurance in healthcare organisations at different levels of care among adult patients with a variety of longstanding medical conditions and who use healthcare on a regular basis. Using the subscales "Personal continuity - GP/specialist knows me", "Personal continuity - GP/specialist shows commitment" and "Team/ cross-boundary continuity" to assess different contexts of healthcare is considered to capture the concept "continuity of care". However, the NCQ-N's usefulness should be further evaluated among other patient groups, including younger people, patients with acute disorders and those with mental health problems.

\section{Additional file}

Additional file 1: Alternative factor models tested for NCQ-N. (TIFF $110 \mathrm{~kb}$ )

\section{Abbreviations}

CFA: confirmatory factor analyses; CFI: comparative fit index; FIML: Full Information Maximum Likelihood; GP: General practitioner; ICC: Intra-class correlation; NCQ: Nijmegen Continuity Questionnaire; NCQ-N: Norwegian version of Nijmegen Continuity Questionnaire; RMSEA: root mean square error of approximation; SRMR: standardized root mean square residual

\section{Acknowledgements}

We thank Marjolein Memelink Iversen at Western Norway University of Applied Science for helping us with translation and adaptation of the Nijmegen Continuity Questionnaire to Norwegian.

Funding

No external funding was received for this research project.

\section{Availability of data and materials}

The raw data are the property of the research unit in the Bergen Health Authority (Helse Bergen) and are available on reasonable request.

\section{Authors' contributions}

$\varnothing \mathrm{H}, \mathrm{MH}$ and SG developed the project idea, worked on the translation of the NCQ-N and contributed to writing the paper. JA and ØH performed the statistical analyses. AU contributed to writing the paper and interpreting the results. All authors read and approved the final manuscript.

\section{Ethics approval and consent to participate}

The Regional Committee for Medical and Health Research Ethics in Western Norway approved this study (references number 2014-1636). Written consent from all participants was also obtained.

\section{Consent for publication}

Not applicable.

\section{Competing interests}

The authors declare that they have no competing interests.

\section{Publisher's Note}

Springer Nature remains neutral with regard to jurisdictional claims in published maps and institutional affiliations.

\section{Author details}

${ }^{1}$ Department of Global Health and Primary Health Care, University of Bergen, PO-box 7804, N-5020 Bergen, Norway. ${ }^{2}$ Centre for Habilitation and Rehabilitation in Western Norway, Bergen Local Health Authority, Bergen, Norway. ${ }^{3}$ Department of Primary and Community Care, Radboud University Nijmegen Medical Centre, Nijmegen, The Netherlands. ${ }^{4}$ Centre for Clinical Research, Haukeland University Hospital, Bergen, Norway.

Received: 27 February 2017 Accepted: 7 November 2017

Published online: 21 November 2017

\section{References}

1. van Walraven C, Oake N, Jennings A, Forster AJ. The association between continuity of care and outcomes: a systematic and critical review. J Eval Clin Pract. 2010;16(5):947-56.

2. Schers $H$, Webster $S$, van den Hoogen $H$, Avery A, Grol R, van den Bosch W. Continuity of care in general practice: a survey of patients' views. Br J Gen Pract. 2002;52(479):459-62.

3. Tarrant C, Dixon-Woods M, Colman AM, Stokes T. Continuity and trust in primary care: a qualitative study informed by game theory. Ann Fam Med. 2010;8(5):440-6.

4. Saultz JW, Lochner J. Interpersonal continuity of care and care outcomes: a critical review. Ann Fam Med. 2005;3(2):159-66.

5. Gruneir A, Bronskill SE, Maxwell CJ, Bai YQ, Kone AJ, Thavorn K, Petrosyan Y, Calzavara A, Wodchis WP. The association between multimorbidity and hospitalization is modified by individual demographics and physician continuity of care: a retrospective cohort study. BMC Health Serv Res. 2016; 16(1):1-9.

6. Worrall G, Knight J. Continuity of care is good for elderly people with diabetes: retrospective cohort study of mortality and hospitalization. Can Fam Physician. 2011;57(1):e16-20.

7. Haggerty JL, Pineault R, Beaulieu MD, Brunelle Y, Gauthier J, Goulet F, Rodrigue J. Practice features associated with patient-reported accessibility, continuity, and coordination of primary health care. Ann Fam Med. 2008; 6(2):116-23 
8. Uijen AA, Schers HJ, Schellevis FG, van den Bosch WJ. How unique is continuity of care? A review of continuity and related concepts. Fam Pract. 2012;29(3):264-71.

9. Freeman GK. Progress with relationship continuity 2012, a British perspective. Int J Integr Care. 2012;12:e128.

10. Haggerty JL, Reid RJ, Freeman GK, Starfield BH, Adair CE, McKendry R. Continuity of care: a multidisciplinary review. BMJ. 2003;327(7425):1219-21.

11. Waibel S, Henao D, Aller M-B, Vargas I, Vázquez M-L. What do we know about patients' perceptions of continuity of care? A meta-synthesis of qualitative studies. Int J Qual Health Care. 2012;24(1):39-48.

12. Freeman $G, H$ jortdahl $P$. What future for continuity of care in general practice? BMJ. 1997, 1870:314(7098)

13. Baker R, Mainous lii AG, Gray DP, Love MM. Exploration of the relationship between continuity, trust in regular doctors and patient satisfaction with consultations with family doctors. Scand J Prim Health Care. 2003;21(1):27-32

14. Frederiksen HB, Kragstrup J, Dehlholm-Lambertsen B. Attachment in the doctor-patient relationship in general practice: a qualitative study. Scand J Prim Health Care. 2010;28(3):185-90.

15. Wensing M, Hermsen J, Grol R, Szecsenyi J. Patient evaluations of accessibility and co-ordination in general practice in Europe. Health Expect. 2008;11(4):384-90.

16. Ministry of Health and Care Services: Regulation relating to a Municipal Regular GP Scheme. Oslo; 2000. In: http://www.regjeringen.no/en/dep/hod/ dok/lover_regler/reglement/2000/regulation-relating-to-a-municipal-regul. html?id=420530. Acessed 2 Sept 2017.

17. Ministry of Health and Care Services: The coordination reform. Proper treatment - at the right place and right time. In: St.meld. nr. 47(2008-2009). Oslo; 2009.

18. Berendsen AJ, de Jong GM, Meyboom-de Jong B, Dekker JH, Schuling J. Transition of care: experiences and preferences of patients across the primary/ secondary interface - a qualitative study. BMC Health Serv Res. 2009;9(1):1-8.

19. Kripalani S, LeFevre F, Phillips CO, Williams MV, Basaviah P, Baker DW. Deficits in communication and information transfer between hospital-based and primary care physicians: implications for patient safety and continuity of care. JAMA. 2007;297(8):831-41.

20. Jee $\mathrm{SH}$, Cabana MD. Indices for continuity of care: a systematic review of the literature. Med Care Res Rev. 2006;63(2):158-88.

21. Saultz JW. Defining and measuring interpersonal continuity of care. The Ann Fam Med. 2003;1(3):134-43.

22. Uijen AA, Schers HJ, van Weel C. Continuity of care preferably measured from the patients' perspective. J Clin Epidemiol. 2010;63(9):998-9.

23. Bentler SE, Morgan RO, Virnig BA, Wolinsky FD. Do claims-based continuity of care measures reflect the patient perspective? Med Care Res Rev. 2014; 71(2):156-73.

24. Uijen AA, Heinst CW, Schellevis FG, van den Bosch WJ, van de Laar FA, Terwee CB, Schers HJ. Measurement properties of questionnaires measuring continuity of care: a systematic review. PLoS One. 2012;7(7):e42256.

25. Uijen AA, Schellevis FG, van den Bosch WJ, Mokkink HG, van Weel C, Schers HJ. Nijmegen continuity questionnaire: development and testing of a questionnaire that measures continuity of care. J Clin Epidemiol. 2011;64(12):1391-9.

26. Uijen AA, Schers HJ, Schellevis FG, Mokkink HG, van Weel C, van den Bosch WJ. Measuring continuity of care: psychometric properties of the Nijmegen continuity questionnaire. Br J Gen Pract. 2012;62(600):e949-57.

27. Beaton DE, Bombardier C, Guillemin F, Ferraz MB. Guidelines for the process of cross-cultural adaptation of self-report measures. Spine (Phila Pa 1976). 2000;25(24):3186-91

28. MacCallum RC, Browne MW, Sugawara HM. Power analysis and determination of sample size for covariance structure modeling. Psychol Methods. 1996:1(2):130.

29. Hooper D, Coughlan J, Mullen MR. Structural equation Modelling: guidelines for determining model fit. Electronic Journal of Business Research Methods. 2008;6(1):53-60.

30. Lt H, Bentler PM. Cutoff criteria for fit indexes in covariance structure analysis: conventional criteria versus new alternatives. Struct Equ Model Multidiscip J. 1999:6(1):1-55.

31. Wheaton B. Assessment of fit in Overidentified models with latent variables. Sociol Methods Res. 1987;16(1):118-54.

32. Schumacker RE, Lomax RG: A beginner's guide to structural equation modeling: psychology press; 2004.

33. Terwee CB, Bot SD, de Boer MR, van der Windt DA, Knol DL, Dekker J, Bouter LM, de Vet HC. Quality criteria were proposed for measurement properties of health status questionnaires. J Clin Epidemiol. 2007;60(1):34-42.
34. Cohen J. Statistical power analysis for the behavior science. Lawrance Eribaum Association: Hillsdale, NY; 1987.

35. Team; RC. R: A language and environment for statistical computing. Austria: R Foundation for Statistical Computing Vienna; 2017.

36. Rosseel Y: lavaan: An R Package for Structural Equation Modeling. 2012 2012, 48(2):36

37. Harzing A-W. Response styles in cross-national survey research: a 26-country study. International Journal of Cross Cultural Management. 2006;6(2):243-66.

\section{Submit your next manuscript to BioMed Central and we will help you at every step:}

- We accept pre-submission inquiries

- Our selector tool helps you to find the most relevant journal

- We provide round the clock customer support

- Convenient online submission

- Thorough peer review

- Inclusion in PubMed and all major indexing services

- Maximum visibility for your research

Submit your manuscript at www.biomedcentral.com/submit
Biomed Central 